\title{
RESISTING CONTROL OF NEGLECTED TROPICAL DISEASES: DILEMMAS IN THE MASS TREATMENT OF SCHISTOSOMIASIS AND SOIL-TRANSMITTED HELMINTHS IN NORTH-WEST UGANDA
}

\author{
MELISSA PARKER*, TIM ALLEN† AND JULIE HASTINGS* \\ * Centre for Research in International Medical Anthropology, Brunel University, UK \\ and $\dagger$ DESTIN, London School of Economics, UK
}

\begin{abstract}
Summary. A strong case has recently been made by academics and policymakers to develop national programmes for the integrated control of Africa's 'neglected tropical diseases'. Uganda was the first country to develop a programme for the integrated control of two of these diseases: schistosomiasis and soil-transmitted helminths. This paper discusses social responses to the programme in Panyimur, north-west Uganda. It shows that adults are increasingly rejecting free treatment. Resistance is attributed to a subjective fear of side-effects; divergence between biomedical and local understandings of schistosomiasis/bilharzia; as well as inappropriate and inadequate health education. In addition, the current procedures for distributing drugs at a district level are problematic. Additional research was carried out in neighbouring areas to explore the generalizability of findings. Comparable problems have arisen. It is concluded that the national programme will not fulfil its stated objectives of establishing a local demand for mass treatment unless it can establish more effective delivery strategies and promote behavioural change in socially appropriate ways. To do so will require new approaches to social, economic and political aspects of distribution. There are reasons why populations infected with the 'neglected tropical diseases' are themselves neglected. Those reasons cannot just be wished away.
\end{abstract}

\section{Introduction}

'Controlling Africa's neglected diseases is one of the most convincing ways to make poverty history,' (Molyneux et al., 2005, p. 106).

Over the last few years, a compelling case has been made to develop national control programmes for the integrated control of Africa's neglected parasitic diseases, including schistosomiasis (otherwise known as bilharzia) and soil-transmitted helminths (World Health Organization, 2002; Editorial of the Lancet, 2004; Hotez, 
2005; Molyneux et al., 2005, Fenwick, 2006). The strength of the case rests upon the following points: first, there are a number of drugs with a proven track record of success which can be cheaply manufactured and easily administered to affected populations; second, it is more economical to administer these drugs as one integrated, top-down, biomedical intervention rather than through multiple vertical structures running side-by-side; and third, it is likely that significant reductions in overall child and adult mortality and morbidity can be achieved if relatively small proportions of public health finance directed towards the control of HIV/AIDS, TB and malaria are re-directed towards the integrated control of some of the neglected, parasitic diseases. These arguments are particularly potent in the light of data revealing that sub-Saharan Africa has fallen behind other regions in public health and poverty indicators; and a new political will (manifested by the Millennium Development Goals and the Marshall Plan for Africa) to 'make poverty history'. The Bill and Melinda Gates Foundation, persuaded by the merits of the above arguments, recently donated US\$30 million to the Schistosomiasis Control Initiative (SCI), Imperial College, to oversee the integrated control of schistosomiasis and soil-transmitted helminths in six African countries: Uganda, Tanzania, Zambia, Niger, Burkina Faso and Mali.

Uganda was the first of these countries to design a five-year national control programme to control schistosomiasis and soil-transmitted helminths. The programme began in 2003. In accordance with the World Health Assembly's Global Target, it is attempting to treat $75 \%$ of school-aged children and adults in regular contact with contaminated water with praziquantel and albendazole. These are the drugs of choice for schistosomiasis and soil-transmitted helminths respectively and they are being distributed, free of charge, on an annual basis over five years. In so doing, it is anticipated that adults and children will become so aware of the benefits of treatment to their overall health and well-being, that families will be willing to pay for treatment in clinics when the programme comes to an end.

Recent publications suggest that the programme has successfully treated children attending school in the majority of districts within Uganda (Kabatereine et al., 2006, 2007). However, these publications also report that adult uptake of the drugs is more mixed, and that it varies between districts. For instance, $91 \%$ and $84.5 \%$ of adults are reported to have taken praziquantel and albendazole in 2003/4 (the first year of the project) in Wakiso and Bugiri districts whereas $66 \cdot 8 \%$ and $48 \cdot 8 \%$ of adults took praziquantel and albendazole in Nebbi and Arua districts respectively. This variation is crucial to understand because adults are much more able to exercise choice (and reject treatment if they so choose) than children treated by their teachers on school premises. Even if children come to appreciate benefits from treatment, the success of the national control programme depends upon generating a demand for the drugs among adults.

The research presented in this paper documents social responses to the national control programme in Panyimur, Nebbi district, north-west Uganda. Schistosoma mansoni (one of the three main types of schistosomiasis) has been endemic in this part of Uganda for a long time (Nelson, 1958; Ongom \& Bradley, 1972; Ongom et al., 1972; Kabatereine et al., 1992), and the reported uptake of drugs among adults in the first year of the project was promising $(66 \cdot 8 \%)$. However, the uptake of drugs declined 
in 2005. The paper, therefore, addresses the following questions: Why are adults who, by any criteria, are poor and eking out a living in a hot, under-resourced and remote part of Uganda, choosing not to swallow drugs that will rid them of infections that cause significant morbidity and mortality? How can these problems be rectified in the context of promoting integrated control?

The paper is divided into three parts to address these questions. Part one describes the research site, and emphasizes the economic and political context in which the national control programme is being delivered. The second part of the paper presents the results, including data showing a decline in the uptake of praziquantel and albendazole in 2005, compared with 2004. It also discuss waning enthusiasm for the programme and highlights three key issues: fear of treatment; a divergence between biomedical and local understandings of schistosomiasis/bilharzia; and attitudes to conveying health advice and the provision of treatment. The third part of the paper discusses the wider implications of the research in Panyimur in the light of research undertaken in Pandara village, Nebbi district and Wanseko, Masindi district. It is argued that integrated control in north-west Uganda will not be successful without significant policy adjustments. These include the vigorous promotion of 'biomedical evangelism' (whereby biomedical facts about schistosomiasis and soil-transmitted helminths and the rationale for repeated treatment are disseminated in ways that convince affected populations); and an endeavour to distribute drugs and promote behavioural change in socially appropriate ways.

\section{Panyimur, north-west Uganda: the research site}

Panyimur sub-county, Nebbi district, is located in north-west Uganda. For administrative purposes, Panyimur sub-county is divided into three parishes: Ganda, Boro and Nyagakei. A census undertaken by the local council in 2004 indicated that the population for these parishes was 5448, 5834 and 9427 respectively. The majority of the population residing in Panyimur sub-county are Alur; and most of them live on the north-west shores of Lake Albert. They speak a Lwo language that is very similar to that of the Acholi and Langi to the east, but have longstanding social connections with other groups, notably Lendu, Lugbara and Madi, who have migrated into the area and were in the past integrated into small chiefdoms, recognizing the authority of ritually important chiefs known as rwodi. There is also a long history of migration to and from the region to the south of the lake, and in pre-colonial times, the Alur rwodi had important links with the Bantu-speaking Kingdom of Bunyoro.

Today, political and economic insecurity characterize daily life. The killing of Alur by Lendu just across the border in the Democratic Republic of Congo, and attacks by the Lord's Resistance Army close to the town of Pakwach (located a few miles to the north-east), are the stuff of daily conversation. So is the precarious nature of livelihoods. Dwindling fish reserves in Lake Albert and severe de-forestation are particular concerns. Moreover, the dearth of rain in recent years, as well as the decline in the world price of cotton, has severely restricted the cultivation and potential financial returns from farming. As in the past, labour migration to more affluent regions is an important strategy for young men and some educated women, but such opportunities have become increasingly limited, especially for the unskilled. 
Thus, responses to the question 'how is life?' typically include 'life is hard' (qwotek); 'there is poverty' (can otie); 'there is no rain' (kothope); 'there is no food' (cam ope); 'there is no money' (cent ope); and 'there is sickness' (remo otie). In many ways, they help to capture the difficulties of eking out a living in Panyimur.

Sickness, and the fear of sickness, are constant concerns. People live with an acute awareness of their vulnerability to dangerous ailments, including both biomedically recognized diseases and numerous locally understood afflictions. They can strike at any time; and the difficulties of finding and securing appropriate treatments are ever present. The cost of purchasing medicines from clinics and/or travelling medicine men can be prohibitive; so can visits to an ajoga or other local therapists. The government health facilities are supposed to provide free services, but the static clinics have very erratic supplies of drugs, and the difficulties of reaching either of the local hospitals in Angal and Pakwach are considerable, because public transport is minimal and expensive.

Inadequate facilities are widely viewed by people in Panyimur as symptoms of their marginality. Informants are quick to convey a sense of having been left out of development processes; and they often comment on the fact that they feel excluded, both in national terms and within their own district. With respect to the former, the sub-county is part of the region of Uganda referred to as 'West Nile', and associated with the discredited regime of Idi Amin. Since Presendent Museveni came to power in 1986, the southern part of Uganda has benefited from relatively robust economic growth and some improvements in living standards. The people of Panyimur are conscious of not sharing in these changes. They often complain that this has been a deliberate strategy, a kind of punishment for Amin's regime (from which they say they have not even benefited), and for the regimes of Milton Obote and Tito Okello, which were associated with linguistically related Langi and Acholi to the east (for recent detailed discussion of these issues, see Leopold, 2005, and Allen, 2006a). Like other northerners, it has made them distrustful of southerners who visit the sub-county and tell them how to behave.

With respect to the district, Panyimur is different to other areas. A way of life linked to fishing, fish processing and fish marketing sets the population apart. District officials in Nebbi town often talk about lake dwellers and those living near the Nile as 'difficult', 'stubborn' and 'un-cooperative'. Among people in Panyimur, aid agencies are commonly mentioned as the only means of securing resources for social projects, but most of those that have worked in the sub-county have left. Some informants are even envious of populations inhabiting the war zone to the east, where they imagine hundreds of non-governmental organizations are running basic services and giving away material items such as food, soap and grain.

\section{Methods}

Fieldwork took place in February 2005, and for a period of three and a half months between May 2005 and August 2005. The research team was made up of three anthropologists, one with a long-standing interest in social and behavioural aspects of schistosomiasis (Parker, 1992, 1993, 1995), one with regional expertise dating back to the 1980s (Allen, 1988, 1991, 1992, 1996, 1997, 2006a, 2006b), and one with medical 
training (Hastings, 2005). The team worked closely with staff from SCI, Imperial College; the Ministry of Health, Kampala, and the vector control officer for Nebbi district. Four locally trained researchers assisted with both the translation of interviews and data collection.

Fieldwork involved participant observation in a wide range of settings in Panyimur sub-county. This included a total of 300 open-ended, unstructured interviews. The research involved visits to homesteads, talking to fishermen at landing sites on the shores of Lake Albert, 'hanging out' in one of the lodges in Panyimur town, and talking to people as they passed through the markets etc. Those interviewed also included twenty local healing specialists (known as ajogas), nine village elders, fifteen health care providers (such as the vector control officer for Nebbi district, clinical officers and health workers at health centres throughout Panyimur sub-county), ten school teachers and twelve political figureheads (such as local council chairmen that had been elected at the village (LC1), parish (LC2) and sub-county level (LC3)).

In the last five weeks of fieldwork, the team explored the generalizabilty of findings, both within Panymur and in neighbouring areas. With respect to the former, interviews were undertaken with adult men and women in Ganda parish at their homes. The choice of homes visited was based on the Ministry of Health registers documenting the uptake of praziquantel and albendazole in 2004 and/or 2005. Every tenth 'household' listed in the registers was selected (although in many cases the 'household' in the registers turned out to represent adults living in more than one home). With respect to comparison with neighbouring areas, additional fieldwork was undertaken in Pandara village, Panyango sub-county, Nebbi district, where the population is also mostly Alur, and Wanseko, a town located directly across Lake Albert from Panyimur in Buliisa sub-county, Masindi district, where there is a mixed population of migrants and longer-term residents (and the local languages spoken include Lunyoro and Lougungu as well as Lwo).

In Pandara, the availability of Ministry of Health registers enabled the team to repeat the selection exercise in Ganda Parish. One in ten registered 'households' were visited, and 20 semi-structured interviews were carried out. In Wansenko, Ministry of Heath registers were mostly missing, so similar random selection of 'households' was not possible. Fifty semi-structured interviews were carried out with adult men and women, based on visits to every third home; and two group meetings were arranged by two of the three LC1 chairmen. These were attended by 27 and 31 adults respectively. In addition, four of the six drug distributors resident in the area were interviewed, as well as four biomedical practitioners based at Buliisa, the nearest health centre.

Interviews in Panyimur and Pandara were usually conducted in the Alur language, but a few took place in English or Swahili. In Wanseko, interviews were undertaken in the local languages (which included languages spoken by the Alur, the Bunyoro and the Bungungu). Most open-ended interviews were tape-recorded and subsequently transcribed into English. Wherever possible, interviews were undertaken in a relaxed and open manner; and a great deal of emphasis was given to establishing trust and rapport with informants. While an endeavour was made to discuss similar themes with each interviewee (such as their experiences of treatment in 2004 and 2005), it was 
also the case that efforts were made to elicit information about other aspects of misfortune and healing, and daily life more generally. Typically, adults were visited in their homesteads, and once the rationale for the research had been explained, the interview began. More often than not, a small crowd gathered round each informant and many of these people contributed to the interview too. Indeed, their views were actively solicited. So, in many ways, the majority of interviews were akin to impromptu focus group discussions rather than one-to-one interviews. They capture the dominant subjective concerns that are widely expressed and debated by people living in this part of Uganda.

\section{Adult uptake of drugs in Panyimur}

There are 49 villages in the three parishes that make up Panyimur sub-county. Praziquantel and albendazole were distributed, free of charge, to adults and children living in all 49 villages in 2004 and 2005. To facilitate distribution, every village was provided with one or more registers with a view to documenting the name, age and height of adults and children on a household-by-household basis. The number of praziquantel and albendazole tablets taken by each individual in 2004 and 2005 was also recorded. Analysis of the available data from the local Ministry of Health registers showed that a total of 6511 adults were given praziquantel and albendazole in 2004, and 2037 of these were re-treated in 2005 . To put it another way, 4474 adults $(68.7 \%)$ were not re-treated in 2005.

It is important to note the limitations of these data. First, these figures are based on incomplete data as there were registers available for all twelve villages in Ganda parish and fourteen of the eighteen villages in Boro parish, but only five of the nineteen villages in Nyakagei parish. The others had 'gone missing'. Second, the system of distribution throughout the sub-county differed between 2004 and 2005, and in neither year followed the guidelines provided by SCI, which intended the drugs to be swallowed in front of locally elected drug distributors. In 2004, local politicians were asked to oversee the distribution of drugs and this involved LC1 chairmen distributing drugs on a household-by-household basis. There is no way of knowing, however, whether everyone allocated drugs in 2004 swallowed them, and it is likely that the figures for 2004 convey a misleadingly high response rate (as several informants told us that some people stored their drugs for a day when they felt really sick, and others sold them or gave them to relatives when they fell sick). By contrast, the therapy was directly observed in 2005. Adults were asked to take praziquantel under the gaze of health workers and their helpers at health centres throughout the sub-county. However, observations at one of the distribution sites revealed that some people were being allowed to take the drug away and take it in their own time (namely, teachers, religious leaders, business people, government officials, relatives and some of the friends of the health workers). There is, of course, no way of knowing how many people were allowed to do this and whether or not the people concerned saved the tablets, sold them or swallowed them as intended. In spite of these limitations, the available data suggest that the majority of people in Panyimur were not re-treated in 2005. The next section sheds light on waning enthusiasm for the national control programme in 2005. 


\section{Fear of treatment}

First, there was widespread concern about the side-effects associated with swallowing the tablets. Indeed, it would not be an exaggeration to say that the issue was raised at virtually every interview undertaken. Not everyone experienced side-effects, but almost all informants had experiences within their immediate or extended families of individuals who had taken the drugs and subsequently experienced illness for several days, and in some cases, several weeks. Concerns about the severity of the side-effects experienced in 2004 undoubtedly generated fear and antipathy towards swallowing the drugs in 2005. The following quotes illustrate their fears:

\footnotetext{
We fear the drug ... it is strong and powerful ... and it is not wise to take it unless you have food stored in the house. This drug can knock you out for more than a week at a time.
}

When I took the tablet, 'praziquantel', [in 2004] it disturbed me for 2 to 3 weeks ... I am a fisherman [and] I cannot afford not to fish. That is why I did not take it [in 2005].

It should be noted that informants such as those quoted above rarely mentioned albendazole by name, but in rejecting praziquantel they were effectively rejecting albendazole, as this was given out at the same time. For this reason, references made to praziquantel are placed in inverted commas. In addition, it should be observed that informants were familiar with the term 'bilharzia', but their understandings rarely coincided with biomedical conceptions of schistosomiasis. Local references to 'bilharzia' are therefore placed in italics.

Several people expressed their concern about the strength and power of "praziquantel' by refusing to take it if they felt unwell on the day of distribution. Thus, a fisherman spoke about his wife in the following way: 'she was sick and weak, and didn't have the strength to take it'. Others felt that if they were harbouring other infections then it was inadvisable to take 'praziquantel'. For instance, a woman, chatting on her way back from collecting water at the pump, said: 'people say "Don't take that drug, if you are HIV positive." Is that true?' She decided not to take the drug in June 2005 as she thought she might be infected with HIV and her body was too weak to cope with 'praziquantel'.

Fear of the side-effects associated with 'praziquantel' was also acute among those living far from the distribution point and those unable to take the drug on a full stomach. Ironically enough, some informants felt that they were too poor to risk taking the drug. To quote:

I live far from the distribution site and they were telling people to take there. I feared the side-effects so I didn't take it.

You suffer from severe diarrhoea for so many days ... you are out of work and don't have enough to eat so you can't survive.

Informants also expressed concern and fear that treatment with 'praziquantel' leads to infertility and miscarriage. For instance, married men in Ganda parish expressed concern that their wives had not conceived since the 2004 mass treatment campaign; and a group of fisherman from a different part of the parish said:

We heard it can make us barren ... impotent ... these drugs can make our wives abort the fetus

... many believe this. 
In a similar vein, a political representative for another sub-county within Nebbi district said: 'pregnant women are fearing if they take the drug, it will lead to miscarriage'; and a secretary to a local politician gave voice to a more invidious concern when he stated that:

The treatment for bilharzia can cause a woman to abort so women, particularly, are afraid to take 'praziquantel' ... women want to give birth frequently, and they think the Ministry [of Health] wants to reduce the birth rate [in this part of the country].

The idea that the Ugandan government is using public health interventions to weaken populations in the north is much discussed in Panyimur, and concern is not restricted to the national control programme for schistosomiasis and soil-transmitted helminths. At the time of this fieldwork, for example, there was some discussion as to whether the USA government was colluding with the Ugandan government to reduce the birth rate in this part of Africa.

A further theme emerging from fieldwork undertaken in Panyimur concerns a fear of over-dosing. Local politicians and other villagers, in particular, expressed a concern that incorrect quantities of drugs were being administered as a consequence of allocating drugs according to height, rather than weight. As one person put it: 'You can be thin and tall and given too much; or short and fat and given too little.' Similarly, an elderly man said: 'Why do they measure height? [After all] you can be young and tall (and take too many tablets) or old and short and take too few tablets.' He went on to describe how he knew a woman who lived close to the lake whose son was taller than her and took more tablets than her. This was 'very discouraging' for the woman concerned.

Concerns over the dosage links to a widespread fear of side-effects associated with treatment for bilharzia, as well as fears that the drug, 'praziquantel', can actually kill. A fisherman, in the presence of a group of eight others, said:

There was confusion in the measurement of height. A young child of seven years was measured and given 6 tablets, so there were complications. The child who took 6 tablets died.

This reference to death was one of 25 accounts of adults and children that allegedly died soon after swallowing 'praziquantel' in 2004. Other accounts that emerged spontaneously in the course of interviews with adults in Ganda parish include the following:

People died from taking the drug [in 2004] ... they were not sick before ... we know of three people that died.

It is a very powerful drug ... if you take it on an empty stomach, it can make you very sick ... it can even kill you.

A fisherman, in the presence of about 30 fishermen, also said:

We know of six people who died [from 'praziquantel' in 2004] ... they were overdosed because of lack of measurements and they were anaemic.

There was much nodding in agreement as he spoke. And a clinical officer at a health centre gave voice to local peoples' concerns that there may be ulterior motives behind the programme when he said: 
People fear the drug ... there are rumours that the government is killing people with this drug programme. Someone died after treatment [2004] ... they were sick before treatment but [he] died so people think the drug can kill. They are suspicious.

\section{Comments on reported fears}

None of the side-effects reported above (including fears of infertility, miscarriage and death) has been verified by clinicians, as the necessary resources are not currently available. However, Kabatereine (2000) and Kabatereine et al. (2006) have drawn attention to side-effects arising from treatment for $S$. mansoni in neighbouring Masindi district, including diarrhoea and abdominal pain. Kabatereine et al. also refer to an 'independent evaluation' of the national control programme, which noted local concerns about mortality arising from treatment (Kabatereine et al., 2006, p. 213). However, Kabatereine et al. (2006) go on to say that mortality arising from treatment is not 'credible', given the research that shows that praziquantel and albendazole are safe and efficacious.

There is indeed strong clinical evidence indicating that this is the case (see, for example, Bergquist, 2002), and much higher doses of praziquantel than are used in schistosomiasis treatment are routinely recommended for treatment of cysticercosis. Even if it was the case that a seven-year-old child was given six tablets (as alleged in the quote above), significant adverse reactions would not be expected (personal communication with Narcis Kabatereine, October 2006).

Nevertheless, the persistent reporting of severe side-effects in Panymur, including instances of mortality, need to be taken seriously. It is possible that relatively intense, short-term side-effects have been underestimated, particularly among people that are immuno-compromised, under-nourished and/or suffering from other parasitic infections. Moreover, in this particular context, it is just as important to understand and overcome local misconceptions about treatment, as there is no doubt that 'praziquantel' is perceived to be an aggressive and powerful drug. Indeed, the political representative for the sub-county revealed that he, too, had been 'scared' to take the drugs as he feared their strength. The next section discusses local understandings of bilharzia and shows that it is not going to be possible to overcome these fears without engaging with local perspectives.

\section{Local understandings of bilharzia}

Local understandings of the biomedical symptoms associated with $S$. mansoni may be divided into two broad areas. First, the symptoms may be interpreted as a sign of witchcraft or a locally understood ailment rather than manifestations of a parasitic infection. These explanations may exclude other explanations or exist alongside them. Second, symptoms may be associated with okudi, a general word for worms or, more specifically, okudi bilharzia. However, local understandings of the aetiology of okudi bilharzia do not necessarily match biomedical understandings of the aetiology of S. mansoni. In fact, local informants, including those associated with formal health care services, were rarely able to explain or describe the life-cycle and symptoms associated with infection by $S$. mansoni. The two areas are discussed in turn: 


\section{Symptoms of S. mansoni and locally understood ailments}

The most commonly cited local ailment believed to cause symptoms similar to those associated with patients heavily infected with $S$. mansoni is awola. Symptoms of awola include a swollen stomach, diarrhoea and overall body ache. Awola may also result in the afflicted person vomiting blood, a symptom that a biomedical practitioner associates with ascites - a serious and sometimes fatal complication arising from infection with $S$. mansoni. However, awola is not caused by an invading pathogen. It is an illness that is inflicted on an individual by a witch due to envy. The intention is to make someone so ill that they might die. It is sometimes referred to as a jok illness (as jok is a term used to describe certain kinds of spirits or spiritual force). If awola is suspected, it is often said that the only curative practice that is effective is treatment by a kind of witch doctor known as an ajoga. There is, however, some debate locally about this, in part because an ajoga is likely to be possessed by spirits. Some Christians view such possession as 'satanic'. There are, therefore, certain awola treatment specialists who deny being witchdoctors and, in certain respects, mimic biomedical practitioners (although their remedies are derived from local herbs and roots, the efficacy of which is sometimes said to be revealed in dreams). Whatever the case, treatment of awola involves several visits to an awola specialist who 'sucks' out a sticky substance from the person's 'stomach' (i.e. magically removes it from the abdomen). The presence of this substance confirms the illness as awola. If an ajoga is consulted, therapy will also involve séances to placate certain spirits.

Treatment of people affected by awola is widespread in Panyimur sub-county. It is also commonly believed that treatment of awola with biomedical drugs from the health centre is dangerous. The health of the afflicted person will deteriorate and they may even die. It is, however, acceptable to go to the health centre after awola has been diagnosed and treated, because drugs such as paracetemol and septrin are thought to assist with the side-effects. The following extract from an interview with a young mother illustrates the above points:

Mother: If you have awola and you go for injection it can kill you. It is a witch disease (jajok).

It can come on any living person, children and adults. You have stomach ache, vomit, diarrhoea

... If you are given any medication you just die.

Question: How do you know it's awola?

Mother: You will get to know when you take the medicine and the condition worsens, then you will know. Adults may not die, but children do.

Question: How do you treat awola?

Mother: You don't get medicine ... The one who heals, sucks it out.

Such beliefs have clear implications for the national control programme. They are underlined in the following quote:

Awola is a problem ... people think when they are troubled by 'worms' that it's awola so they don't go for mass treatment drugs.

Bilharzia

While concerns about awola are prevalent in Panyimur, so is awareness of bilharzia. Bilharzia is likely to be an alternative interpretation of symptoms of awola, 
rather than an interpretation that is held simultaneously. It is understood as a type of okudi. Other types of okudi include okudi ascaris, okudi hookworm, okudi amoeba as well as okudi bilharzia. Okudi bilharzia is often said to be the kind of worm most likely to cause ill health. Indeed, one informant referred to it as 'the chairman of worms'. This probably reflects earlier efforts at schistosomiasis control in the area, such as those of an Italian NGO that provided de-worming treatment for three years, immediately before the instigation of the national control programme. However, local use of the term 'bilharzia' does not mean that biomedical understandings of the aetiology of $S$. mansoni are widespread. On the contrary, there are diverse views about how bilharzia is transmitted. There is also ambiguity about the distinctions between different types of worms. In short, beliefs about bilharzia overlap with biomedical understandings of $S$. mansoni, but they do not replicate them.

By way of illustration, a clinical officer in Nebbi district said '[bilharzia] is caused by drinking and bathing in contaminated water'; a senior politician that 'our people here do not understand that you can get it by treading on faeces'; a local politician ( $\mathrm{LC} 1$ chairman) that 'bilharzia is a big concern here as people are drinking dirty water from a contaminated source'; and a Catholic priest advised a man that was vomiting blood and passing blood in his stool (two clinical signs of infection with S. mansoni) to see an ajoga as he had been 'poisoned' (i.e. affected by witchcraft). When one old man was shown a picture depicting the life cycle of $S$. mansoni, he asked how it was possible for tiny worms to enter the pores in his feet and then become so big in his body that they would make noises when he ate. Along similar lines, children in primary schools described okudi bilharzia as being 'like earthworms'; and people living near a borehole located too close to a swampy area at the edge of the Nile would not drink from it, because they sometimes found big black okudi bilharzia in the pumped water, and were concerned about infection.

With respect to the symptoms associated with bilharzia or okudi bilharzia, the following symptoms are widely associated with this infection: diarrhoea, bloody diarrhoea, swollen stomach, and vomiting blood (ngok rimo). The situation is further complicated by the fact that these signs and symptoms are simultaneously understood within a discourse about eating and the shortage of food. Worms have to be fed. They live in the stomach and eat food. They cause hunger, stomach ache, anaemia and fatigue. When they become hungry, they are said to growl in the stomach. An elderly fisherman said:

... the worms in the body make a sound in the tummy ... drrrr'; and a 52-year-old woman, too sick to work in her garden, stated: 'I am disturbed by worms ... they are always there, they give me stomach pain and bring hunger. I can hear them in the morning ... at times there is weakness and also general body pain.

The widespread comment 'we are disturbed by worms' may sometimes refer to infection with okudi bilharzia; but there are other times when it refers to hunger. Food insecurity is a major aspect of life in Panyimur and disturbance with worms gives voice to the struggle to survive.

With reference to this last point, it should be recognized that the vast majority of people living in Panyimur view okudi and okudi bilharzia, in particular, as an 
undesirable yet inevitable part of life. They are acutely aware that their livelihoods depend on the lake and/or river and there is nothing they can do to alter this. As one elderly fisherman said:

How can we avoid the lake? We are fisherman, if we do not fish we do not survive, we will die.

This disease is always a problem for us.

The next section discusses the implications of research detailing local understandings of bilharzia for strategies seeking to promote health education and the integrated control of parasitic diseases.

\section{Attitudes to conveying health advice and the provision of treatment}

To date, health education has not been prioritized in north-west Uganda. An attempt was made to provide advice about the treatment and prevention of schistosomiasis/ bilharzia in 2004, but this was not repeated prior to treatment in 2005. Apart from the dearth of information, it is also the case that the quality of information available and the style of delivery are problematic. To elaborate: health education materials such as pamphlets and posters about schistosomiasis, as well as ideas expressed at meetings with 'the community', embrace biomedical approaches; and dialogue typically takes the form of telling others how to think and behave. The complex relationship between biomedical understandings of sickness and local understandings of misfortune (including, but not restricted to, biomedical misfortune) is, therefore, overlooked; as well as the day-to-day realities of eking out a living in a context where it is virtually impossible to avoid contact with contaminated water.

This is unfortunate. There is a rich and detailed ethnographic literature documenting local understandings of health, sickness and misfortune in Uganda (see, for example, Allen, 1991, 1992, 1997, 2006a; Middleton, 1960; Reynolds Whyte, 1997; Mwanga et al., 2004; Southall, 1953 [2004]); and many other parts of East Africa (see, for example, Evans-Pritchard, 1937; Janzen, 1978; Geissler, 1998). Much of this literature highlights the pluralistic nature of indigenous medical systems and demonstrates the way in which biomedical understandings of aetiology are incorporated into local understandings of sickness.

With respect to the people of Panyimur, it is not uncommon for adults to discuss responses to sickness that involve seeking out biomedical treatment whilst simultaneously consulting a range of local healers, including herbalists, priests and ajogas. Staff from the Ministry of Health express little interest in understanding the nature of medical pluralism. This reflects a dearth of qualified personnel willing and able to spend time with people understanding their concerns and anxieties; as well as a belief that local responses to sickness and misfortune are largely irrelevant to those concerned with the delivery of the national control programme. The implications of this for public policy are wide ranging. It is clearly not going to be possible to create a demand for treatment with praziquantel and albendazole unless there is an engagement with local understandings and responses to the signs and symptoms of parasitic infections. This does not mean that local understandings should be taken at face value or that local healers should necessarily be professionalized or incorporated into the official public health system. The point is simply that the Ministry of Health 
does not have the capacity or desire to impose a treatment regime, so a case for repeated doses of drugs being a necessity has to be made in a way that is convincing in a local context. At present, this is not the case. Rather, the activities of the national control programme are viewed as tangential to the realities of daily life, and to both disparage local knowledge and ignore the locally understood capacities of respected healers living in the community. The next two sub-sections on 'health education' and 'delivery strategies' elaborate these points in more detail.

\section{Health education}

With respect to health education, interviews revealed that few adults had an adequate understanding of the rationale for repeated treatment for schistosomiasis and soil-transmitted helminths, including those distributing drugs. For instance, the idea that it might be possible to be infected and feel healthy was novel to virtually every villager interviewed - as well as most local biomedical practitioners. It is hardly surprising, then, that no one was conversant with the idea that taking drugs on a regular basis can reduce the possibility of developing serious complications from infection. Indeed, many people stated that they had rejected treatment in 2005 on the grounds that they thought it was inappropriate to take drugs if you felt 'well'. To quote a local politician:

It is not in our culture to take drugs unless we are sick ... the idea of taking a drug when you are well is strange to people here ... people do not wish to take it, especially as it can make you sick.

And a male informant resident in Ganda parish said:

... people really think about it, before buying medicine as it costs so much money. If you don't feel sick then you don't take medicine. Medicine is for sick people. The health workers turn you away if you don't feel sick, so why take 'praziquantel' now if you feel well?

The provision of detailed information about the aetiology and signs and symptoms of infection with $S$. mansoni and soil-transmitted helminths, as well as the rationale for the programme and its relationship to prevention more generally, is crucial, but this needs to be conveyed in ways that can be understood. During fieldwork in Panyimur, we did not come across any printed health education materials in the local language. There was a small amount of material in English, and this was used in primary schools, including a cartoon booklet about a small boy infected with 'bilharzia'. In addition, there is a diagram of the life-cycle of schistosomiasis/bilharzia in the registers used to document the uptake of drugs within the community. However, these sources of information are not widely available and, in some respects, they are unhelpful. The cartoon booklet does not explain why it is so bad to become infected with schistosomiasis/bilharzia or why repeated treatment is an appropriate response. Instead, it suggests that children should avoid going into rivers and lakes. This advice is untenable in Panyimur sub-county. In addition, both the cartoon booklet and the illustration that appears in the registration books depict the schistosome worms as if they are under a microscope. This seems to be one reason why primary school children and also many adults believe that okudi bilharzia looks similar to earthworms. As part of our research in primary schools, we asked 
children if they could describe the 'bilharzia worm'. Overwhelmingly, the answer was that it was long and black. Similarly, on being shown the illustration in the registration books, people asked how it was possible for such big worms to enter their bodies.

\section{Delivery strategies}

Improving health education materials alone, however, will not be sufficient to reverse the fortunes of the national control programme in Panyimur. There are, in addition, major problems with the delivery of public health information and the drugs. The current methods tend to be resented and resisted because they make manifest social, political and economic hierarchies. They primarily rely upon on a small group of staff, either linked to the district headquarters in Nebbi or the Ministry of Health in Kampala. These staff hold impromptu meetings with local politicians, health care workers and whoever else happens to be around. Those who are sent from Nebbi have a good understanding of aspects of local life, but tend to be disparaging of people living near the lake, accusing them of 'drunkenness', 'stubbornness' and 'promiscuity'. They also feel disempowered by their lack of resources and by the scrutiny of the Ministry of Health in Kampala. Meanwhile, those who are occasionally sent to Panyimur from Kampala rarely speak the languages used in northern Uganda. On the one hand, their advice is commonly thought by local people to have a hidden agenda; on the other, some of the Kampala staff seemed to find it hard to escape from stereotypes prevalent in the south about 'primitive' northerners. Consequently, members of staff from Kampala were generally rather reluctant to integrate or socialize in Panyimur and their attitudes were made manifest by, for example, a refusal to eat local food and a reluctance to leave their four-wheel-drive vehicle - giving as reasons that people were filthy and would insist upon shaking hands, that local healers who were present were 'Satan' worshippers, or that the sun was just too hot. Their attitude is encapsulated by one who said, as a casual aside, whilst driving through the town of Masindi (the last major town one reaches before crossing the river Nile to north-west Uganda): 'This is where civilization ends' (see Leopold, 2005, pp. 1-48; and Allen, 2006b, for further examples).

Against this background, it is perhaps hardly surprising that existing strategies are greeted with a certain amount of antipathy. People in Panyimur are acutely aware of the disdain that some health educators and biomedical practitioners feel towards them. The problem, moreover, is compounded by the fact that engagement with the integrated programme of disease control by those who are meant to benefit by it requires a large amount of voluntary labour. At international, national and district level, those implementing the programme are paid, but further down the system they are not. 'Communities' are expected to provide volunteers. Local politicians, school teachers, clinic staff and others have been willing to do so, in part, because it lends them status. They also see themselves as assisting their neighbours and relatives; but their enthusiasm is inevitably limited and in the second year of the programme (when fieldwork was undertaken) they persistently expressed irritation at how much they were being asked to do without remuneration, emphasizing that diligently spending several days at a time involved significant opportunity costs. Not only were they not 
being paid, but also they were unable to earn income or obtain food for their families by other means. In meetings with the vector control officer, some of the more outspoken local volunteers vociferously expressed their frustration. In some cases, the problem with 'missing registers' turned out to be a manifestation of this tension: they were being held back by drug distributors until they received some kind of recompense for their work. A few informants made the point that there were temptations to find ways of making money out of selling the drugs across the border in Congo.

Exerting greater control over the distribution and consumption of drugs was the reason given by staff from the Ministry of Health for changing the approach in 2005, whereby drugs were given at clinics under the gaze of a health worker. This certainly eased the burden on drug distributors, although they still felt it was onerous and that they should have been remunerated. However, the change in distribution methods may also have contributed to the decline in reported uptake of drugs in 2005, compared to 2004, particularly among adults living in the remote and hilly parts of the sub-county. The fact that so many adults living next to distribution sites rejected free treatment (for example, $82.2 \%$ of adults in Matusa village, Ganda parish, declined to take drugs for a second time in 2005) suggests, however, that it would be inappropriate to attribute a change in delivery strategy as the primary reason for rejecting drugs.

\section{Wider implications of the research in Panyimur}

So far, the findings presented in this paper relate to fieldwork undertaken in Panyimur, Nebbi district. Additional fieldwork was undertaken in Pandara, Pacego parish, Nebbi district and Wanseko, Masindi district, with a view to exploring the generalizability of key findings. Results emerging from these two field sites are discussed in turn.

Pandara is one of 26 villages in Pacego parish, Panyango sub-county. These villages are located along the western bank of the river Nile and the majority of the population are Alur. Twenty villages had registers documenting the uptake of drugs in 2004 and 2005, one village had a register for 2004 only, and five villages had registers for 2005 only. Drawing upon the available data documenting the number of adults that received treatment in 2004 and 2005, it emerged that 6257 adults came forward for treatment in 2004, but only 1162 returned for treatment in 2005. That is, $81 \cdot 4 \%$ of adults were not re-treated in 2005 .

With respect to Pandara village, a total of 754 adults were treated in 2004, but only ten $(1 \cdot 3 \%)$ returned for treatment in 2005. Twenty semi-structured interviews were undertaken with adults residing in the village about the mass treatment programme and the key issues emerging were the following: a fear of side-effects associated with taking 'praziquantel' (including a fear of over-dosing and a fear of death arising from treatment); a widespread belief in awola and the need for this to be treated by ajogas rather than biomedical practitioners; and concerns about swallowing drugs under the direct gaze of health care workers (rather than being given them to take in one's own time). In addition, the rationale for mass treatment on an annual basis was poorly understood. 
The challenges facing the national control programme in Wanseko are again similar to those described for Panyimur, but in certain respects they are even more acute. Wanseko is located on the shores of Lake Albert, and it can be seen from Panyimur on a clear day. In theory, a ferry operates between the two centres, but it was taken away for repairs in 2004, and to our knowledge, it has yet to return (informants stated that this is because a number of locally powerful people are making money by transporting people in canoes). It is located within one of the southern Ugandan kingdoms, Bunyoro, and the population is relatively heterogeneous. In addition to Lunyoro (the language of the Bunyoro kingdom), many people speak Lougungu, and there are also many Alur migrants.

The central issue emerging during fieldwork was that drugs for the treatment of schistosomiasis and soil-transmitted helminths among adults were widely distributed in 2003, but were poorly distributed in 2004. Unfortunately, it was not possible to enumerate the number of adults that received treatment in 2003 and 2004 respectively as it proved enormously difficult to locate some of the registers. Only two of the three registers for 2003 could be found and none of the registers for 2004 could be located, in spite of making considerable efforts to find them at the district headquarters in Masindi, the nearby health centre at Buliisa and the homes of various drug distributors in Wanseko. However, on the basis of the 108 adults that we asked, 15\% stated that they were given the opportunity to take the drug twice. (Research undertaken by SCI in 2004 confirms a low coverage rate, and it has been estimated at 'no more than 30\%', personal communication with Russell Stothard.)

This failure to distribute drugs in Wanseko was surprising. While migrants, in particular, were very poor, it is a place more fully integrated into the Ugandan national economy than Panyimur; and a long-standing research programme on schistosomiasis has been running in Bugoigo, a little further south in Masindi district. The reason for the failure was found to be linked to local politics and social relations. Two related factors came to light. First, Wanseko has a much more heterogeneous population than that of Panyimur. There has been a history of conflict between long-term residents of the Bunyoro kingdom and the more recent migrants (including those from Nebbi district as well as those from the Congo). There is a great deal of distrust and antipathy between some neighbours. Consequently, 'community mobilization' presents additional challenges. Second, the spirit of volunteerism that was found to be problematic in Panyimur was almost completely absent, and this was compounded by the way on which volunteers were appointed. Whereas in Panyimur and Pandara, local council politicians distributed the tablets themselves (partly to enhance their local standing), in Wasenko, staff from Masindi district headquarters arranged with local counsellors the election of three male and three female drug distributors. It would seem that the local counsellors in Wasenko had other sources of income and status. As a consequence, those elected as volunteers had markedly less incentive than the local counsellors in Panyimur and Pandara to be seen as working for nothing. Indeed, most adults interviewed in Wasenko were incredulous about the expectation that they should invest valuable time and energy in distributing drugs to people who were not friends or relatives. Several informants, including staff at Buliisa health centre, were open about the fact that taking on responsibility for distributing drugs was a calculation based on how much might be given in the form of food and 
other commodities (such as bicycles), how much might be earned by selling drugs in the open market, and/or whether or not it was worth accumulating a personal store of the drugs in case a member of their own family should fall ill in the future. One of those selected as a volunteer pointed out that he has eight children between the ages of two and thirteen. He owns one cow and fishes for other people as he does not own a canoe. His wife makes rush mats that are sold in the market and the income generated from these activities is minimal. With so many dependants, it is simply not feasible to spend a week handing out drugs free of charge. As an official from Masindi district said: 'volunteerism is actually not realistic'.

\section{Conclusions}

Top-down, vertical, biomedical interventions are notoriously difficult to successfully administer. If they are not linked to an effective system to ensure compliance (such as enforceable legal measures), then they are dependent on the voluntary cooperation and support of local populations. Recent endeavours to ensure that condoms are widely distributed and used to prevent the transmission of HIV; as well as endeavours to reduce the transmission of diarrhoeal diseases by hand-washing; and acute respiratory infections by the administration of vitamin A tablets demonstrate how difficult it can be to bring about behavioural change. The challenges presented to the Ugandan national control programme for schistosomiasis and soil-transmitted helminths are no different. Indeed, in some ways, they are more acute. Schistosomiasis and soil-transmitted helminths are chronic infections that many people live with for years, even decades, before developing clinical indicators of morbidity. The treatment is widely perceived by local people to be strong and potent, allegedly causing short-term sickness and occasional fatalities. In a social, political and economic context where people struggle for survival, feel excluded from the political process and frustrated by the fact that 'development' appears to be moving at a much faster pace in more favoured parts of the country, it is, perhaps, inevitable that resistance to well-intentioned interventions has emerged. Refusing treatment is a form of what Scott (1985) has called 'weapons of the weak'.

That said, the national control programme for the integrated control of schistosomiasis and soil-transmitted helminths must be the right way forward. It provides an opportunity to contain infection and reduce the chances of developing clinical signs of morbidity. Schemes to improve sanitation and water supply could potentially break cycles of transmission, but it is unrealistic to suppose that they will be large enough and swift enough to bring about significant changes in the foreseeable future. Regular treatment is the only viable option. So, contrary to the arguments presented by critics such as Utzinger et al. (2003), the issue is not the underlying approach. It is the specific strategies for implementing it.

How, then, can the programme achieve one of its objectives of generating a demand for drugs whereby adults seek treatment on a regular basis? This paper has shown that increasing the availability of education materials and revising some of the existing procedures for disseminating information must be prioritized. In addition, serious endeavours should be made to communicate with local people in local languages. While it is probably untenable and, possibly, counterproductive to try to 
incorporate local healers into public health services, it would be useful to persuade some of these healers to assist in alleviating anxieties about biomedical treatment for bilharzia. There is a need, too, for direct challenges to be made to local beliefs and practices that adversely affect health. People cannot be expected to make appropriate choices if they do not know why they are being asked to do certain things. In short, vigorous efforts are required to promote biomedical evangelism.

Here, there are grounds for optimism as there were innumerable indications during fieldwork that local beliefs about sickness and misfortune, including beliefs about bilharzia and awola, were much discussed and far from static. For example, a 76-year-old married man, concerned about the implications of local beliefs in awola for the national control programme, made the following observation:

Awola is a poisonous term ... it has made so many people die ... if a child is suffering from, say, malaria, people say 'it's awola', but how can someone suck diseases which are in the blood by the mouth? It's impossible! In my household we do not believe in awola. If a child is suffering from fever ... then the child must be taken to the dispensary for medication. We totally refuse the idea of awola...

In a slightly different vein, it was striking how quickly fears and anxieties about 'praziquantel' could be alleviated, if time was spent discussing the rationale for mass treatment, and in 2006, there were reports that some people in Panyimur complained when treatment was only made available in schools, due to lack of funds (personal communication with Narcis Kabatereine, October 2006).

However, to make the programme work, organizational changes will be necessary. Distribution of drugs is never politically neutral. In this case, it will only work if the power dynamics of distribution are socially acceptable. In other words, the right people have to be chosen to distribute and monitor drugs. This should primarily include influential local people who are adequately supported by the national and district authorities. It may also involve empathetic non-locals. This may sound obvious and, indeed, it is recommended in the SCI guidelines, but at present it is not what happens in those parts of Uganda in which this research was undertaken. Those selected at all levels will also have to receive some form of remuneration. It cannot be assumed that voluntary labour is a viable option for most people living in impoverished conditions.

In addition, it may be necessary to consider socially appropriate compliance procedures. Usually, discussions with people in Panyimur, Pandara and Wanseko ended with a long and detailed explanation about parasitic infections, the life-cycle of $S$. mansoni, the rationale for mass treatment etc. We would then ask for questions. A very common response was the following: 'Why are there no by-laws to stop people infecting others? People can be seen defecating and urinating in the lake, but no one stops them. Many people do not have pit latrines. Why can't rules be made to make them have one?' Older people still remember public health programmes for malaria, sleeping sickness and other diseases that were linked to compliance procedures. This used to be a major preoccupation of chiefs and headmen. If bilharzia is really so serious, why, people asked us, is it not dealt with in the same way? It seems a reasonable question.

All the foregoing discussion leads to a final observation about the Ugandan programme. People we interviewed, including the District Medical Officer, were 
bemused by the idea that a demand for treatment will arise from those benefiting, and that praziquantel and albendozole will then be purchased indefinitely at the end of the current period of free distribution. Even if people become aware of significant changes to their overall well-being, which is currently not the case, how will effective demands be made for continued mass treatment? The people living near Lake Albert have a limited voice, and they have insufficient income for marketing to become an economic proposition for private pharmacists. Some may complain to the staff of SCI and local vector control personnel. But it will not have much effect unless the initiative itself continues to receive funds and donated drugs, or a highly subsidized supply becomes available from another source. At present, it is hard to see a viable alternative to sustained international aid and persistent international lobbying. In this respect, the situation described here is unlikely to be exceptional. There are reasons why the 'neglected tropical diseases' have been so widely ignored, and those reasons cannot just be wished away.

\section{Acknowledgments}

This paper is based on fieldwork funded by SCI, Imperial College, under the auspices of the Bill and Melinda Gates Foundation; and the authors are grateful to Professor Alan Fenwick and Fiona Fleming from SCI for their assistance. In Uganda, the authors are grateful to their assistants: Albert Wutham, Stanley Bright Jhopacu, Philip M.C and Nstori Onen, as well as the chief Rwoth of Panyimur and their many informants who gave their time so freely. They are also indebted to staff from the Ministry of Health, Uganda, especially Dr Narcis Kabatereine, Oneba Dickson, Faith Kyembabazi and Jackson Rwaheru. A final word of thanks is reserved for Melissa Parker and Tim Allen's children, Joshua and Rachael, who proved to be wonderful fieldworkers and opened doors in unexpected and helpful ways.

\section{References}

Allen, T. (1988) Coming home: the international agencies and returnees in West Nile. Journal of Refugee Studies 1(2), 166-175.

Allen, T. (1991) The quest for therapy in Moyo District. In Bernt-Hansen, H. \& Twaddle, M. (eds) Changing Uganda. James Currey, London, pp. 149-161.

Allen, T. (1992) Upheaval, affliction and health: a Ugandan case study. In Bernstein, H., Crow, B. \& Johnson, H. (eds) Rural Livelihoods: Crises and Responses. Oxford University Press, Oxford, pp. 217-248.

Allen, T. (ed) (1996) In Search of Cool Ground: War, Flight and Homecoming in Northeast Africa. Africa World Press/UNRISD/James Currey.

Allen, T. (1997) The violence of healing. Sociologus 47(2), 101-128.

Allen, T. (2006a) Trial Justice: The Lord's Resistance Army and the International Criminal Court. Zed Press, London.

Allen, T. (2006b) Northern Uganda revisited. Africa 78(3), 427-435.

Bergquist, N. R. (2002) Schistosomiasis: from risk assessment to control. Trends in Parasitology 18(7), 309-314.

Evans Pritchard, E. E. (1937) Witchcraft, Oracles and Magic among the Azande. Clarendon Press, Oxford. 
Editorial (2004) Thinking beyond deworming. Lancet 364, 981-983.

Fenwick, A. (2006) New initatives against Africa's worms. Transactions of the Royal Society of Tropical Medicine and Hygiene 100, 200-207.

Geissler, P. W. (1998) 'Worms are our life', part 1. Understandings of worms and the body among the Luo of western Kenya. Anthropology and Medicine 5(1), 63-79.

Hastings, J. (2005) Survival, sickness and schistosomiasis: local curative practices and responses to a mass treatment programme in Panyimur, northwest Uganda. Dissertation submitted in partial fulfillment of the requirements of an MSc in Medical Anthropology, Brunel University.

Hotez, P., Bethony, J., Brooker, S. \& Albonico, M. (2005) Eliminating neglected diseases in Africa. Lancet 365, 1089.

Janzen, J. M. (1978) The Quest for Therapy: Medical Pluralism in Lower Zaire. University of California Press, Berkeley.

Kabatereine, N. B. (2000) Schistosoma mansoni in a fishing community on the shores of Lake Albert at Butiaba, Uganda: epidemiology, morbidity, re-infection patterns and impact of treatment with praziquantel. PhD thesis, Faculty of Science, University of Copenhagen, Denmark.

Kabatereine, N. B., Ariho, C. \& Christensen, N. O. (1992) Schistosoma mansoni in Pakwach, Nebbi district, Uganda, 40 years after Nelson. Tropical Medicine and Parasitology 43(3), 162-166.

Kabatereine, N. B., Brooker, S., Koukounari, A., Kazibwe, F., Tukahebwa, E. M., Fleming, F. M., Zhang, Y., Webster, J. P., Stothard, J. R. \& Fenwick, A. (2007) Impact of a national helminth control programme on infection and morbidity in Ugandan schoolchildren. Bulletin of the World Health Organization 85, 97-99.

Kabatereine, N. B., Tukahebwa, E., Kazibwe, F., Nawwangye, H., Zaramba, S., Brooker, S., Stothard, J. R., Kamenka, C., Whawell, S., Webster, J. P. \& Fenwick, A. (2006) Progress towards countrywide control of schistosomiasis and soil-transmitted helminthiasis in Uganda. Transactions of the Royal Society Tropical Medicine and Hygiene 100, 208-215.

Leopold, M. (2005) Inside West Nile: Violence, History and Representation on an African Frontier. James Currey, Oxford.

Middleton, J. (1960) Lugbara Religion. Oxford University Press, Oxford.

Molyneux, D. H. (2004) 'Neglected diseases' but unrecognized successes - challenges and opportunities for infectious disease control. Lancet 364, 380-383.

Molyneux, D. H., Hotez, P. J. \& Fenwick, A. (2005) 'Rapid impact interventions': how a policy of integrated control for Africa's neglected tropical diseases could benefit the poor. PloS Med 2 (11), e336.

Mwanga, J. R., Magnussen, P., Mugashe, The Late C. L., Gabone, The Late R. M. \& Aagaard-Hansen, J. (2004) Schistosomiasis-related perceptions, attitudes and treatmentseeking practices in Magu District, Tanzania: public health implications. Journal of Biosocial Science 36, 63-81.

Nelson, G. S. (1958) Schistosoma mansoni infection in West Nile District of Uganda: part 111. The spleen and S. mansoni infection. East Africa Medical Journal 35, 543-547.

Ongom, V. L. \& Bradley, D. J. (1972) The epidemiology and consequences of Schistosoma mansoni infection in West Nile, Uganda. 1. Field studies of a community at Panyagoro. Transactions of the Royal Society of Tropical Medicine and Hygiene 66, 835-851.

Ongom, V. L., Owor, R., Grundy, R. \& Bradley, D. J. (1972) The epidemiology and consequences of Schistosoma mansoni infection in West Nile, Uganda. II. Hospital investigations of a sample from the Panyagoro community. Transactions of the Royal Society of Tropical Medicine and Hygiene 66, 852-863. 
Parker, M. (1992) Re-assessing disability: the impact of schistosomal infection on daily activities among women in Gezira Province, Sudan. Social Science and Medicine 35(7), 877-890.

Parker, M. (1993) Bilharzia and the boys: questioning common assumptions. Social Science and Medicine 37(4), 481-492.

Parker, M. (1995) Living with schistosomes: adaptation, accommodation or severe ill-health? In Boyce, A. J. \& Reynolds, V. (eds) Human Populations: Diversity and Adaptability. Oxford University Press, Oxford, pp. 155-173.

Reynolds Whyte, S. (1997) Questioning Misfortune: The Pragmatics of Uncertainty in Eastern Uganda. Cambridge University Press, Cambridge.

Scott, J. C. (1985) Weapons of the Weak. Everyday Forms of Peasant Resistance. Yale University Press, New Haven/London.

Southall, A. (2004) [1953] Alur Society: A Study in Processes and Types of Domination. International African Institute/Transaction Publishers, London.

Utzinger, J., Bergquist, R., Shu-Hua, X., Singer, B. H. \& Tanner, M. (2003) Sustainable schistosomiasis control - the way forward. Lancet 362, 1932-1934.

World Health Organization (2002) Prevention and Control of Schistosomiasis and SoilTransmitted Helminthiasis: Report of a World Health Organization Expert Committee. World Health Organization, Geneva. 